\title{
Experimental Study on Flow Characters of Salt Hydrate Slurry in Phase Change Temperature Range
}

\author{
Muhammad Irsyad ${ }^{1,2 *}$, Yuli S. Indartono ${ }^{2}$, Ari D. Pasek ${ }^{2}$, and Willy Adriansyah ${ }^{2}$ \\ 1 Mechanical Engineering Department, Engineering Faculty, Universitas Lampung, Indonesia \\ 2 Faculty of Mechanical and Aerospace Engineering, Institut Teknologi Bandung, Indonesia \\ *E-mail: irsyad71@students.itb.ac.id (Corresponding author)
}

\begin{abstract}
One of the efforts in minimizing energy consumption chiller type air conditioning system is the use of phase changing material in secondary refrigerant. Secondary refrigerant functions to obtain heat from the air to cool a room and to release heat in chiller evaporator. Based on working temperature of secondary refrigerant, the fluid can flow in liquid form, and can also be in fluid solid form or slurry at the temperature of its phase change. This research studies the effect of temperature toward flow characteristics, with the parameter analyzed being the pressure decrease and friction coefficient. Besides that, in order to support data analysis, it was initiated by viscosity testing, density and concentration of solid mass. Data taken were viscosity, density, solid mass concentrate, and pressure difference found in copper pipe. Data were taken for several fluid temperatures, and at pressure decrease was added by variation of flow speed. Hydrate salt tested were $\mathrm{CaCl}_{2}$ and $\mathrm{Na}_{2} \mathrm{HPO}_{4}$. Viscosity and density increased with the decrease in temperature. The formation of solid particles within phase change temperature range also gave an impact on the increase in the value of viscosity and density. Pressure drop increased when using hydrate salt fluid. The use of $\mathrm{CaCl}_{2}$ solution resulted in the highest pressure decrease. This salt hydrate has far higher viscosity and density compared to water. This has an effect toward an increase in pressure drop. This increase started to be significant in the phase change temperature area in which solid particle started to form. The same thing happened in the friction coefficient value.
\end{abstract}

Keywords: Phase change temperature, salt hydrate, pressure drop, viscosity, slurry.

ENGINEERING JOURNAL Volume 21 Issue 5

Received 23 November 2016

Accepted 20 February 2017

Published 29 September 2017

Online at http://www.engj.org/

DOI:10.4186/ej.2017.21.5.15 


\section{Introduction}

Air conditioning system is much used in housing and commercial building sectors, such as offices, hotels, hospitals and shopping centers. Energy consumption in this system is considered to be the highest between around $38 \%$ and $65 \%$ [1], [2], [3], so a development to minimize electricity energy consumption is needed. One of the methods being developed at present is the use of PCM in secondary refrigerant.

One of the parts in the research on PCM development for the application in this secondary refrigerant is the study of flow characteristics. This study has needed to be conducted since the using of PCM in secondary refrigerant influence the characteristics of fluid such as density and viscosity. Besides that, in the temperature range of phase change, fluid flows in the form of two-phase flow of solid-fluid or slurry. In air conditioning system PCM experiences formation process of solid particles in the chiller evaporator and the process of melting in the fan coil unit (FCU) or in air handling unit (AHU). The change in properties surely affects the pressure drop in the piping system and gives an impact in the pump energy utilized.

From several studies, they illustrate that the rate of viscosity and density increases with the use of phase change material. Huang et.al. (2010) used PCM of commercial paraffin namely RT 6 and when compared to water, it had higher viscosity rate, but the density was lower [4]. Ma et.al. (2010) using tributhyl ammonium bromide (TBAB) also had higher viscosity and density compared to water [5]. Besides that, the use of PCM also has an impact in the increase in pressure drop. Abbassi et.al. (2010) showed the incident of increase in pressure drop due to increase in solid mass concentration in ice slurry [6]. Indartono et.al. (2006) discovered an increase in friction coefficient due to the use of PCM from trimethylolethane (TME) [7]. Fluid density and viscosity greatly affect pressure drop. Increase in viscosity rate results in increase in pressure drop [8].

In order to obtain viscosity rate from testing using viscometer, capillary pipe can be calculated by using the following equations.

$$
\begin{gathered}
v=\frac{v_{e x p}^{2.441}}{T^{0.21}}+0.079 \\
\eta=\frac{\tau_{w}}{\dot{\gamma}} \\
\tau_{w}=\frac{D .4 P}{4 . L} \\
\gamma=\frac{3}{4} \phi+\frac{1}{4} 8 \tau_{w} \frac{d \phi}{d \tau_{w}} \\
\phi=\frac{8 . u}{D}
\end{gathered}
$$

where $D$ is the diameter of capillary pipe, $\Delta P$ is the decrease in pressure, $L$ is length of capillary pipe, and $u$ is the velocity of fluid flow.

Decrease in pressure can be identified by experiment and calculation using equation of mayor head losses. The value of friction coefficient is a non-dimensional numeral which is used to show the nature of fluid dynamic toward flow losses. The general equation for Newtonian fluid uses Darcy Wisbach equation, as shown in Eq. (6). Specifically for non-Newtonian flow, there are several equations that can be referred to. Thomas equation is used for the condition of turbulence flow as shown in Eq. (7). Snoeck at.al. obtained friction coefficient equation in the form of empirical equation by including the function of solid mass concentration, as shown in Eq. (8) [9]. This equation is a development from Blasius equation with a multiplication factor from solid mass concentration. Blasius equation is shown in Eq. (9).

$$
\begin{gathered}
h_{L_{\text {mayor }}}=f \frac{l}{D} \frac{V^{2}}{2 g} \\
f=0.1988 R e^{-0.211} \\
f_{d}=f=\left(1+0.119 \cdot X_{v . i s}^{2.151} \cdot R e^{0.2422}+0.02415 \cdot X_{v i s}^{0.3996} \cdot d^{-0.2845}\right)
\end{gathered}
$$




$$
f=0.3164 R e^{-0.25}
$$

Dodge and Metzner created a semi empirical correlation equation for fully developed flow in flawless pipe and non-Newtonian flow, as shown in Eq. (10) [10,11]. In this equation, Reynolds numeral used is one that has been modified by Metzner and Reed, as shown in Eq. (11). In this equation parameter $\mathrm{K}$ and $\mathrm{n}$ is inserted in which $\mathrm{K}$ is fluid consistency coefficient and $\mathrm{n}$ is flow behavior index.

$$
\begin{gathered}
\frac{1}{\sqrt{f_{F}}}=\frac{4.0}{n^{0.75}} \log \left(R e_{M R} \sqrt{f_{F}^{2-n}}\right)-\frac{0.4}{n^{1.2}} \\
R e_{M R}=\frac{D u \rho}{K}\left(\frac{4 n}{3 n+1}\right)^{1-n}\left(\frac{8 u}{D}\right)^{1-n}=\frac{D^{n} u^{2-n} \rho}{K^{!} 8^{n-1}}
\end{gathered}
$$

While Buckingham-Reiner made a correlation equation to predict value of friction factor in nonNewtonian fluid of laminar flow, as shown in Eq. (12) [12]. In this equation, a parameter in the form of Hedstrom value is used, as shown in $\mathrm{Eq}$ (13).

$$
\begin{gathered}
f=\frac{64}{R e_{i s}} \cdot\left[1+\frac{H e}{6 \cdot R e_{i s}}+\frac{H e^{4}}{3 \cdot f^{3} \cdot R e_{i s}}\right] \\
H e=\frac{d^{2} \cdot \tau_{o} \cdot \rho_{i s}}{\eta_{i s}^{2}}
\end{gathered}
$$

\section{Materials and Experiment}

\begin{tabular}{|c|c|c|c|c|}
\hline Salt hydrate & Composition & $\begin{array}{l}\text { Melting } \\
\text { temperature }\left({ }^{\circ} \mathrm{C}\right)\end{array}$ & $\begin{array}{ll}\begin{array}{l}\text { Latent } \\
(\mathrm{kJ} / \mathrm{kg})\end{array} & \end{array}$ & References \\
\hline $\mathrm{CaCl}_{2}+\mathrm{H}_{2} \mathrm{O}$ & $40 \%: 60 \%$ & $5.36-5.26$ & 315.57 & [13] \\
\hline $\mathrm{Na}_{2} \mathrm{HPO}_{4}+\mathrm{H}_{2} \mathrm{O}$ & $5.03 \%: 94.97 \%$ & $6.02-1.26$ & 205.94 & [13] \\
\hline
\end{tabular}

This research is an experimental study in which the fluid used in it was salt hydrate from $\mathrm{CaCl}_{2}$ and $\mathrm{Na}_{2} \mathrm{HPO}_{4}$. The fluid composition and nature are summarized in Table 1. Testing was divided into two parts namely property testing related to viscosity, density and concentration of solid mass, also flow losses testing.

Table 1. Fluid composition and thermal properties.
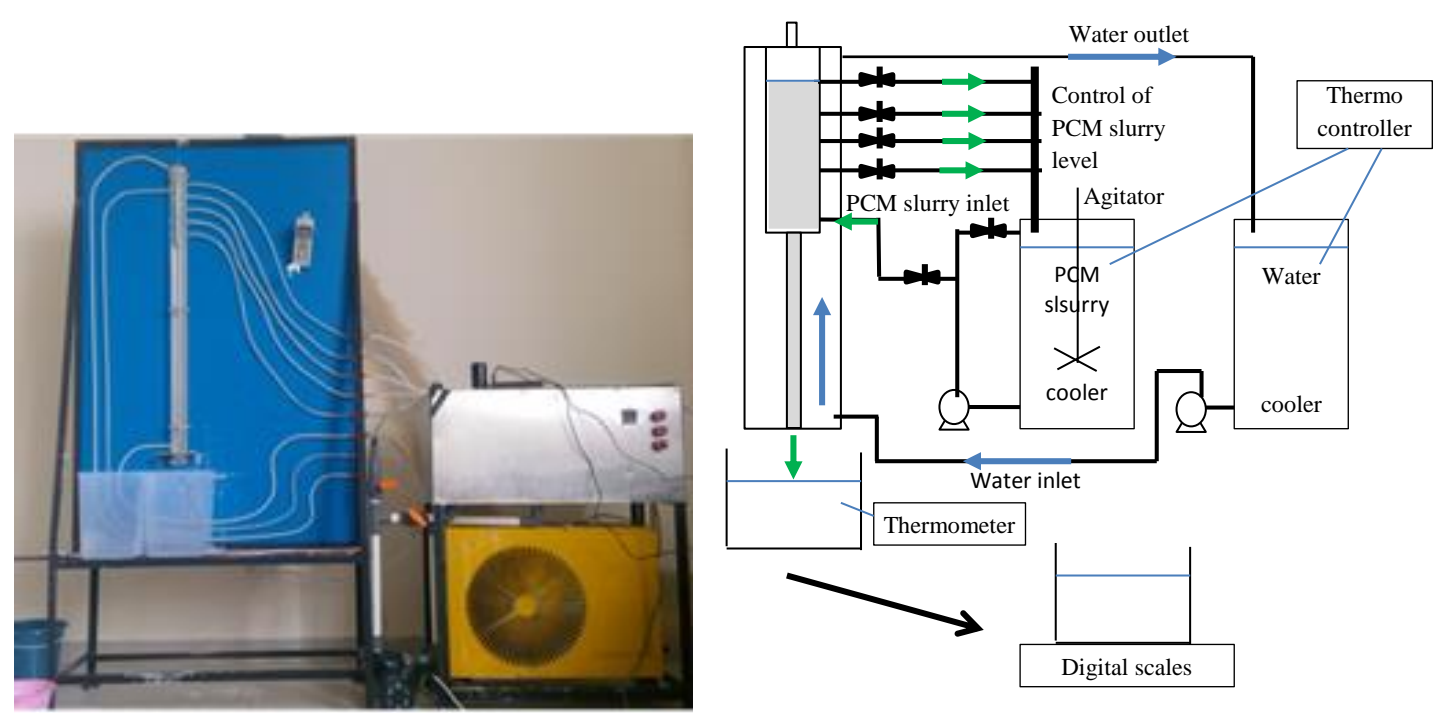

Fig. 1. Photo and schema of viscosity testing to capillary viscometer type. 
Testing equipment of PCM properties was viscometer capillary type, as shown in Fig. 1. Viscometer used capillary pipe with a diameter of $3 \mathrm{~mm}$, length of $790 \mathrm{~mm}$. Variation of water level in the reservoir was controlled at 910, 960, 1005, and $1055 \mathrm{~mm}$. The temperature of test fluid was also maintained by distributing water with the same temperature in the outer part of the line of viscometer, thus thermal energy from the surrounding air could be absorbed by the water. To get a flow rate that varies was done by adjusting the height of the fluid in the pipe reservoir in viscometer. To keep the height of the fluid used in order to remain exhaust valves were channeled back into the cooling bath. After the height of the fluid in the pipe reservoir constant then testing was done to accommodate fluid out of the viscometer for a certain time interval. From the test results was obtained by the mass flow rate of fluid, and then processed to obtain shear stress and shear rate. From the comparison of these two values was obtained for each temperature viscosity testing. Meanwhile, to measure the density was done by using pycnometer sized $200 \mathrm{ml}$. Test fluid inserted into pycnometer and then measured its mass. From the comparison between the mass and volume of the fluid density was obtained for each temperature testing. Solid mass in the slurry have been taken using a sieve with a mesh size 20 . The mass of solid particles was measured and then compared to the overall sample mass slurry to obtain a solid mass concentration.

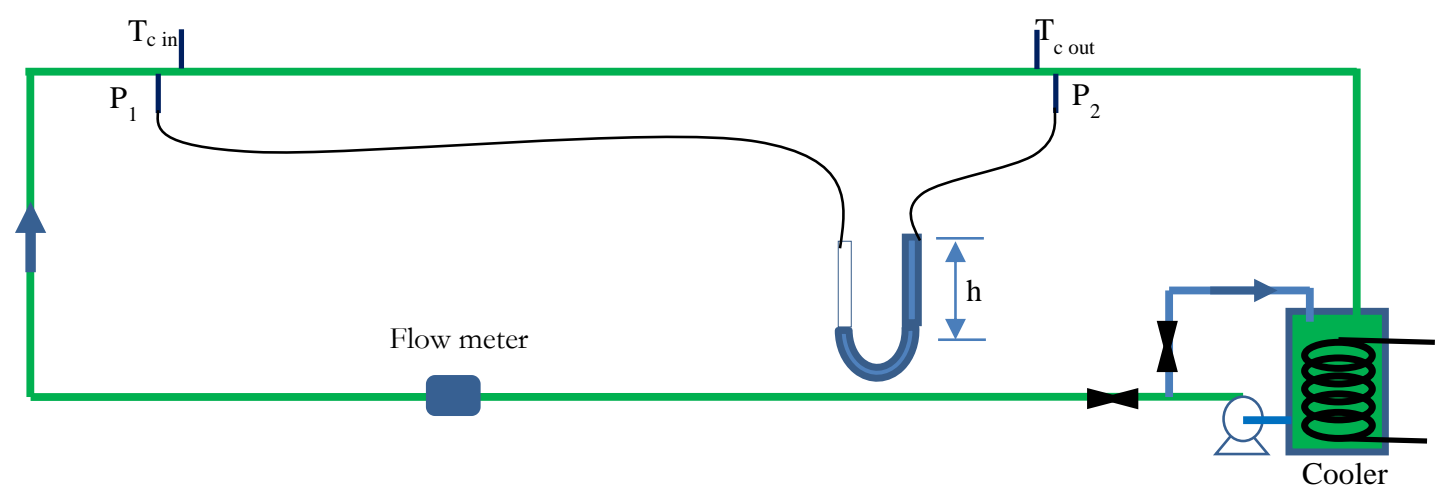

Fig. 2. Scheme of testing equipment of loss-loss flow.

To identify the characteristics of hydrate salt flow, a test was then conducted on test equipment with a scheme shown in Fig. 2. The parameter in this test covered fluid type, fluid temperature, and flow rate. Temperature variation of fluid is at one phase condition which is $20^{\circ} \mathrm{C}$, and at temperature range of phase change: $5^{\circ} \mathrm{C}, 10^{\circ} \mathrm{C}$, and $15^{\circ} \mathrm{C}$. While flow rate variations in testing were $31 \mathrm{pm}, 61 \mathrm{pm}, 91 \mathrm{pm}$, and $121 \mathrm{pm}$. Measuring tools used were as follows: for temperature, using thermocouple type $\mathrm{K}$ and thermometer data logger with the brand Luthron type BTM-4208SD; fluid flow debit, using electromagnetic flow meter with the brand Omega type FMG92; and pressure difference, using manometer $U$ with mercury fluid. Pressure difference was measured in copper pipe of $9.3 \mathrm{~mm}$ diameter with length of test part of $3.2 \mathrm{~m}$. The temperature of the test fluid in the cooling bath was controlled by using thermo controller to get the testing temperature. Retrieval of pressure drop data has been taken at the time of the test section inlet temperature as desired. To maintain the temperature throughout the test pipe, then the whole pipeline installation has been coated with an insulator.

\section{Result and Discussion}

Characteristic analysis of hydrate salt flow in the temperature range of phase change needs to consider rate of density and viscosity of fluid. In this part, salt hydrate characteristics at phase change temperature and pressure drop take place in this condition.

\subsection{Salt Hydrate Properties in Phase Change Temperature}

Hydrate salt formed from $\mathrm{Na}_{2} \mathrm{HpO}_{4}$ and $\mathrm{CaCl}_{2}$ has higher density compared to water. Level of viscosity of both hydrate salts are higher compared to water, as shown in Fig. 3. When hydrate salt is still in one phase that is liquid, temperature decrease from $20^{\circ} \mathrm{C}$ to $15^{\circ} \mathrm{C}$ does not give a significant impact yet toward increase in viscosity. However, when the temperature decreases starting from $14^{\circ} \mathrm{C}$ increase in viscosity 
seemed to be significant. Besides that the viscosity rate is compared to TBAB viscosity data obtained by Hasimoto et. al. (2012) [14], and viscosity rate of micro encapsulates phase change material (MPCM) from n-tetradecane produced by Alvarado et. al. (2004) [15]. The viscosity rate of hydrate salt of this test result has similar tendency as TBAB and MPCM viscosity. Its fluid condition is relatively the same that is in the form of slurry, in which the lower the temperature, the thicker the slurry and the higher the viscosity.

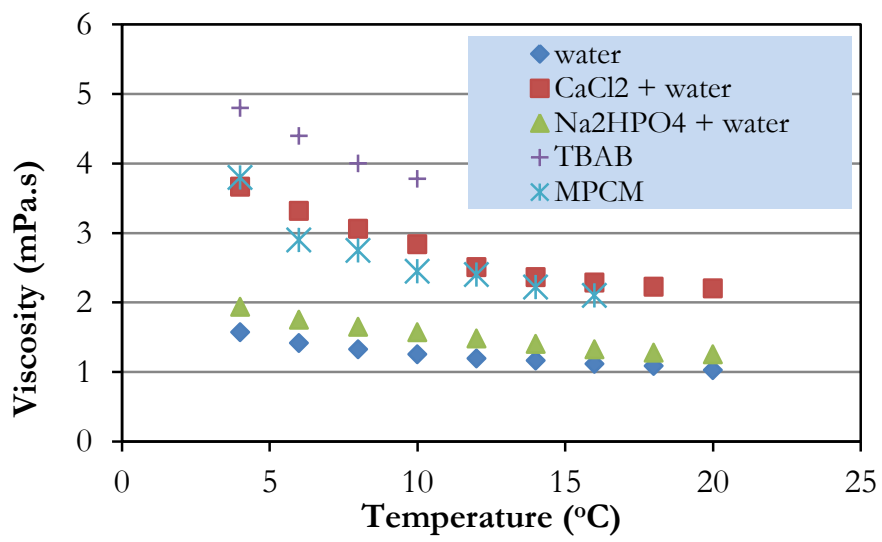

Fig. 3. Fluid Viscosity based on temperature.

Viscosity of salt hydrate from $\mathrm{Na}_{2} \mathrm{HPO}_{4}$ increases with a decrease in temperature, as shown in Fig. 4. The same thing applies for fluid density. This density is also included as a factor affecting the viscosity rate, thus increase in density gives impact on viscosity increase. Besides that also a decrease in temperature causes hydrate salt to form solid particles. In this hydrate salt, solid particles were already formed at $3 \%$ at a temperature of $16^{\circ} \mathrm{C}$ and continues to increase with the decrease in temperature and is starting to be less increasing at a temperature of $6^{\circ} \mathrm{C}$. When the fluid has turned into slurry, the rate of viscosity increased significantly. This is the same phenomenon that occurs in the fluid slurry of nanoparticles. As researched by Rimdusit, et.al. (2011) using benzoxazine monomer and nano particles of $\mathrm{SiO}_{2}$, where increasing concentrations of nanoparticles has improved viscosity value [16]. The relation of fluid temperature toward viscosity for salt hydrate from $\mathrm{Na}_{2} \mathrm{HPO}_{4}$ can be written in the form of Eq. (14). While for density, it is written in the form of Eq. (15).

$$
\begin{gathered}
\eta=0.0017 T^{2}-0.0828 T+2.219 \\
\rho=0.0137 T^{2}-1.1432 T+1071.1
\end{gathered}
$$

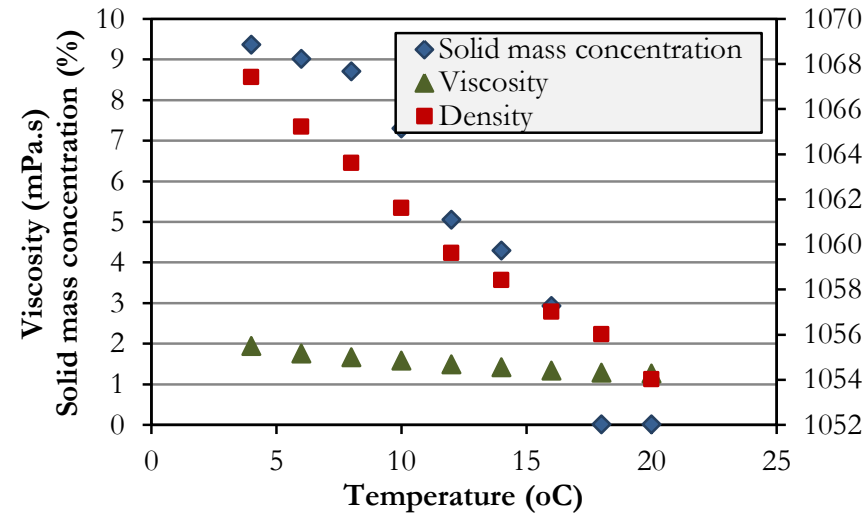

Fig. 4. Fluid characteristics of salt hydrate from $\mathrm{Na}_{2} \mathrm{HPO}_{4}$.

The same thing takes place in the cooling process, salt hydrate from $\mathrm{CaCl}_{2}$, in which the viscosity and density increase with decrease in temperature, as shown in Fig. 5. Decrease in temperature causes the 
movement of molecule to decrease thus the density increases. Besides that decrease in temperature has resulted in the formation of solid particles. Both of these are the cause for viscosity to increase. From the viscosity curve, the relation between temperature and viscosity can be made and written in the form of Eq. (16). The same thing for density, it can be written in the form of Eq. (17).

$$
\begin{aligned}
& \eta=0.0059 T^{2}-0.2337 T+4.5212 \\
& \rho=0.0508 T^{2}-2.2145 T+1410.2
\end{aligned}
$$

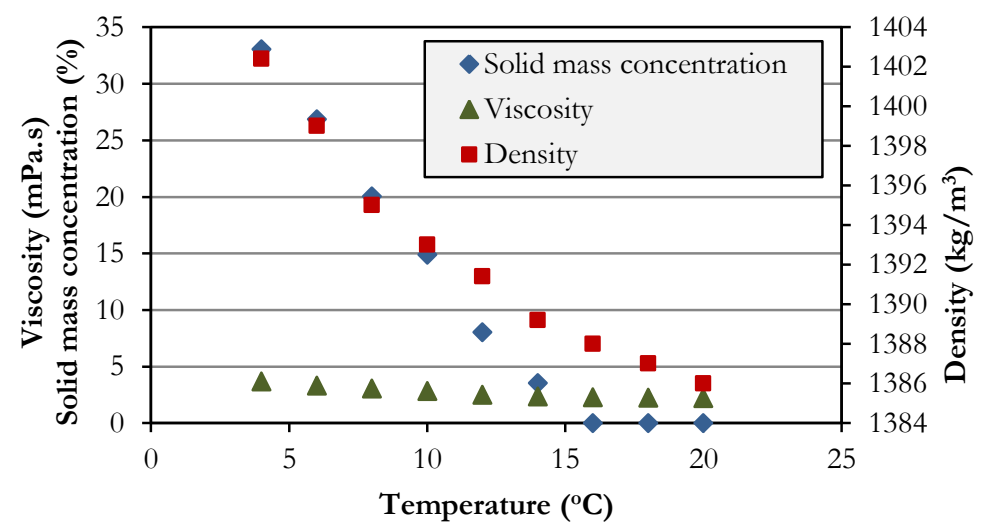

Fig. 5. Fluid nature of hydrate salt from $\mathrm{CaCl}_{2}$.

\subsection{Pressure Drop in Phase Change Temperature}

The utilization of salt hydrate fluid in the piping system causes increase in pressure drop, as shown in Fig. 6. Salt hydrate from $\mathrm{CaCl}_{2}$ gives greater effect toward increase in pressure drop compared to salt hydrate from $\mathrm{Na}_{2} \mathrm{HPO}_{4}$. This material has density and viscosity which was far greater compared to salt hydrate from $\mathrm{Na} 2 \mathrm{HPO}_{4}$. A different thing is shown by salt hydrate from $\mathrm{Na}_{2} \mathrm{HPO}_{4}$, in which the pressure drop is a little higher compared to water, because the viscosity and density rates are slightly higher compared to water.

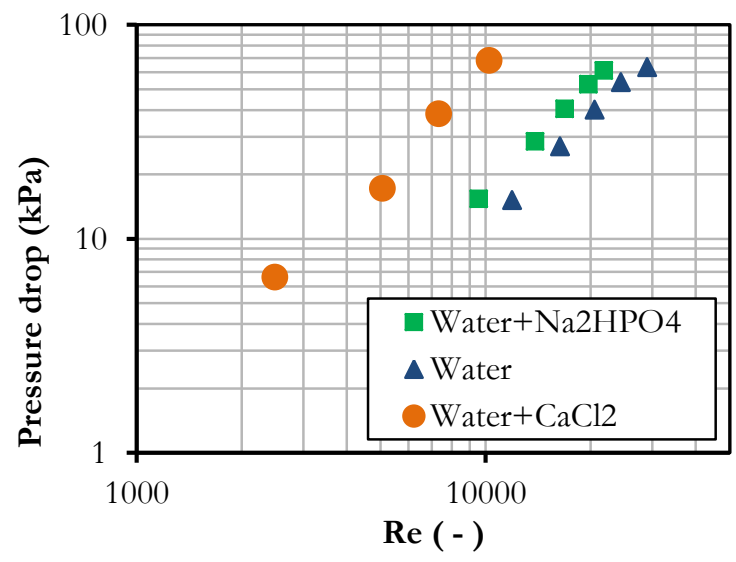

Fig. 6. Comparison of hydrate salt and water pressure drop.

Pressure drop for hydrate salt fluid from $\mathrm{CaCl}_{2}$ in each temperature is shown in Fig. 7. From the curve, it can be seen that the lower the temperature, the pressure drop increases. This is explained by temperature curve toward viscosity shown in Fig. 7(a). In the same Reynolds number, there is an increase in pressure drop with the decrease in temperature. The increase becomes more significant with the increase in Reynolds number. The increase in pressure drop is caused by the increase in rate of viscosity and density. Besides that, there is formation of solid particles in fluid thus the flow is in the form of slurry causing pressure drop to increase also. 


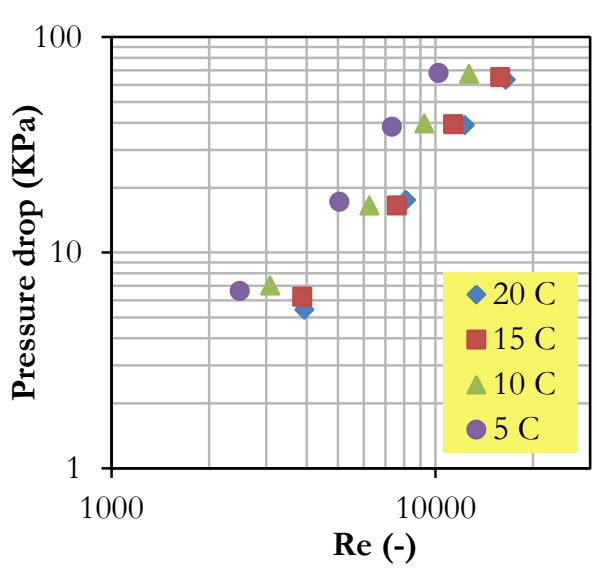

(a) Reynolds number variation

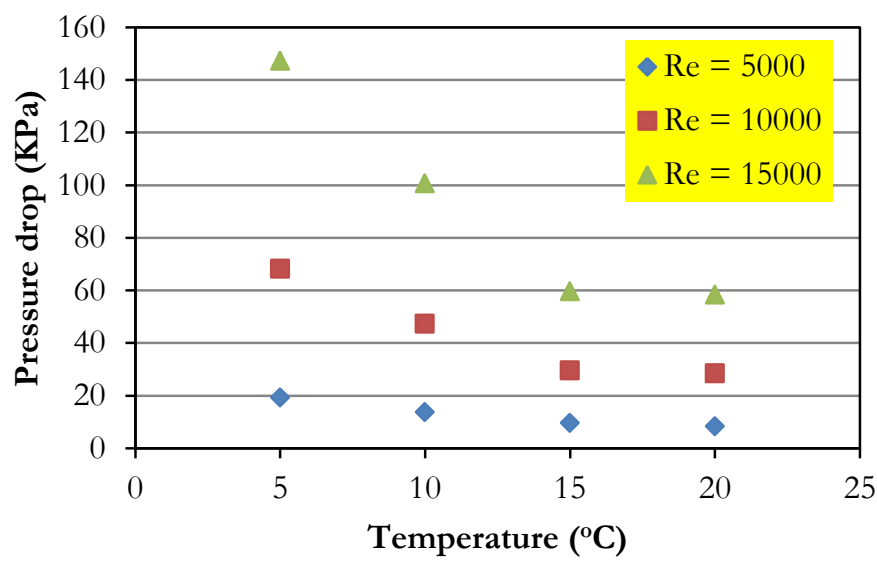

(b) Temperature variation

Fig. 7. Pressure drop of salt hydrate from $\mathrm{CaCl}_{2}$.

Friction factor for both hydrate salts is shown in Fig. 8. This rate is calculated from data of testing result using Darcy-Weisbach equation then compared to the rate of friction factor from several equations. For low concentrations, some researchers conclude still classified as Newtonian fluids, such as ice slurry with a concentration of $6-15 \%$ [17]. So this equation can be used to predict the friction factor. This equation also exact equation, so that can perform calculations on the data of test results. Some researchers are using this equation into account besides to the equation for Non-Newtonian fluid. Among them are Komono et.al (2013) using ice slurry [18], Indartono et.al (2006) using fluid trimethylolethane [7], and Chen at.al (2014) using microencapsulated phase change material from paraffin [19]. Based on the above salt hydrate of $\mathrm{Na}_{2} \mathrm{HPO}_{4}$ still allowing assumed as a Newtonian fluid at a temperature of $5^{\circ} \mathrm{C}$ due to the concentration of the solid mass of only $9.1 \%$, but for the salt hydrate of $\mathrm{CaCl}_{2}$ already exceed the concentration limits. Friction factor for hydrate salt from $\mathrm{CaCl}_{2}$ at a temperature of $10^{\circ} \mathrm{C}$ can be approached with Snoeck equation, since having an almost similar figure. In this equation, the concentration of solid mass is included as variable. While friction factor for salt hydrate from $\mathrm{Na}_{2} \mathrm{HPO}_{4}$ is more suitable to be approached with Thomas equation. This is due to viscosity and density rates which are not much different to water and besides that also the concentration of its solid mass is not too much at lower than $10 \%$.

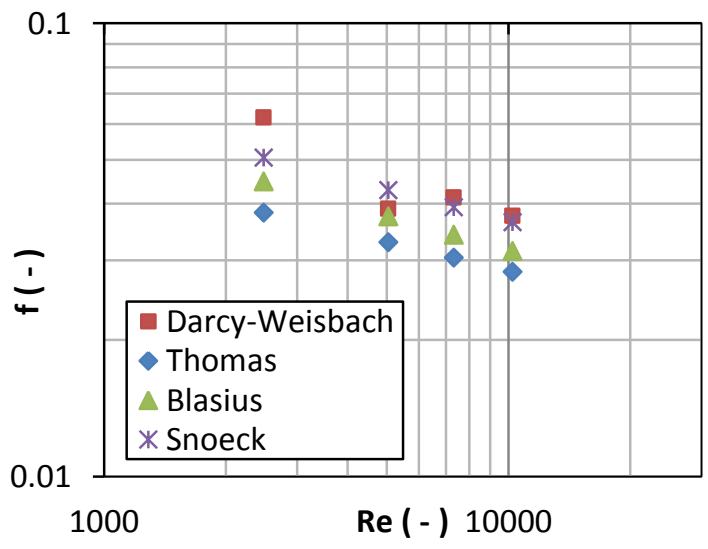

(a) PCM from $\mathrm{CaCl}_{2}$

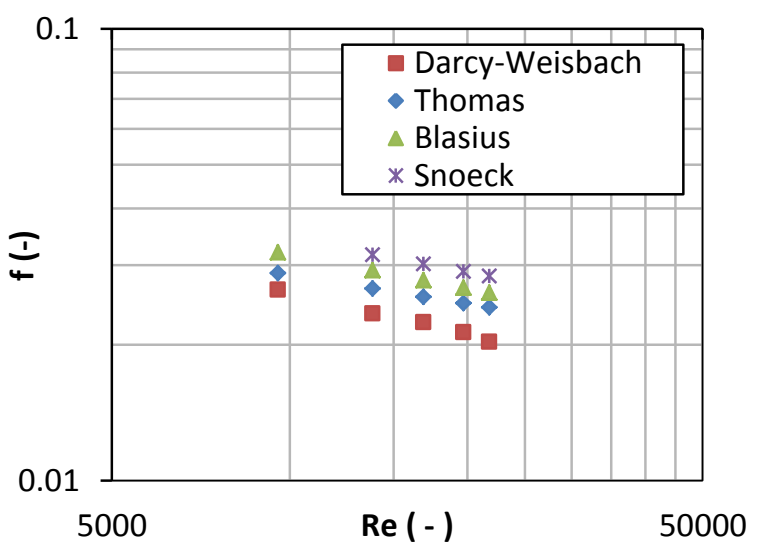

(b) PCM from $\mathrm{Na}_{2} \mathrm{HPO}_{4}$

Fig. 8. Comparison of Friction factor for salt hydrate in temperature of $5^{\circ} \mathrm{C}$. 


\section{Conclusions}

Hydrate salt has higher viscosity and density rates compared to water. Increase in these rates is significant at temperature of phase change. In this condition, the formation of solid particles in fluid takes place thus density and viscosity of fluid increase. This is also a factor that causes increase in pressure drop which is significant in a temperature decrease. Friction factor rate of test and calculation result with Darcy-Weisbach equation can be approached with Snoeck equation for hydrate salt from $\mathrm{CaCl}_{2}$, and Thomas equation for hydrate salt from $\mathrm{Na}_{2} \mathrm{HPO}_{4}$.

\section{Acknowledgments}

The writers cannot successfully conduct the study without support and assistance from many important individuals and institutions. Firstly, the writer's best gratitude is addressed to Indonesia's Ministry of Research, Technology and Higher Education which had provided research grant for this study under University Outstanding Research Project 2016.

\section{References}

[1] J. Xia, T. Hong, Q. Shen, W. Feng, L. Yang, P. Im, A. Lu, and M. Bhandari, "Comparison of building energy use data between the United States and China," Energy and Buildings, vol. 78, pp. 165-175, 2014.

[2] R. Saidur, "Energy consumption, energy savings, and emission analysis in Malaysian office buildings," Energy Policy, vol. 37, pp. 4104-4113, 2009.

[3] JICA Study on Energy Efficiency and Conservation Improvement in Indonesia 2007-2008. [Online]. Available: http://eneken.ieej.or.jp/en/data/pdf/491.pdf

[4] L. Huang, C. Doetsch, and C. Pollerberg, "Low temperature paraffin phase change emulsions," International Journal of Refrigeraation, vol. 33, pp. 1583-1589, 2010.

[5] Z. W. Ma, P. Zhang, R. Z. Wang, S. Furui, and G. N. Xi, "Forced flow convective melting heat transfer of clathrate hydrate slurry in tubes," International Journal of Heat and Mass Transfer, vol. 53, pp. 3745-3757, 2010.

[6] K. E. Abbassi, J. Castaing-Lasvignottes, J. P. Bédécarrats, J. P. Dumas, and A. Mimet, "Energetic performances of a refrigerating loop using ice slurry," Applied Thermal Engineering, vol. 30, pp. 962-969, 2010.

[7] Y. S. Indartono, H. Usui, H. Suzuki, Y. Komoda, and K. Nakayama, "Hydrodynamics and heat transfer characteristics of drag-reducing trimethylolethane solution and suspension by cationic surfactant," Journal of Chemical Engineering of Japan, vol. 39, no. 6, pp. 623- 632, 2006.

[8] M. Jurkowska and I. Szczygiel, "Review on properties of microencapsulated phase change materials slurries (mPCM)," Applied Thermal Engineering, vol. 98, pp. 365-373, 2016.

[9] C. W. Snoeck, S. Walosik, and R. P. Gupta, "Ice slurry transport for district cooling networks, slurry handling and pipeline," in Transport Hydro-Transport, C. Snoeck, Ed. London: Mechanical Engineering Publication Ltd., 1993, pp. 511-524.

[10] P. Zhang and J. Ye, "Experimental investigation of forced flow and heat transfer characteristics of phase change material slurries in mini-tubes," International Journal of Heat and Mass Transfer, vol. 79, pp. 1002-1013, 2014.

[11] A. Metzner and J. Reed, "Flow of non-Newtonian fluids-Correlation of the laminar, transition, and turbulent-flow regions," AIChE J., vol. 1, no. 4, pp. 434-440, 1955.

[12] M. Grozdek, R. Khodabandeh, and P. Lundqvist, "Experimental investigation of ice slurry flow pressure drop in horizontal tubes," Experimental Thermal and Fluid Science, vol. 33, pp. 357-370, 2009.

[13] M. Irsyad, A. Suwono, Y. S. Indartono, A. D. Pasek, and W. C. Mahendra, "Characteristics study of salt hydrate as candidate of secondary refrigerant to chiller type air conditioning system," in Proceeding of Annual National conference on Mechanical Engineering XIII (SNTTM XIII), Depok, 15-16th October 2014, pp. 513-517.

[14] S. Hashimoto and K. Kawamura, "Viscosity reduction with self-assembly of cationic surfactant on tetra-n-butyl ammonium bromide semi-clathrate hydrate aqueous slurry," American Chemical Science Journal, vol. 2, no. 3, pp. 69-85, 2012. 
[15] J. Alvarado, C. Marsh, C. Sohn, and D. Kessler, "Thermophysical properties characterization of microencapsulated phase change material slurry," in Proc. International Refrigeration and Air Conditioning Conference at Purdue, July 12-15, 2004, pp. 1-8.

[16] S. Rimdusit, K. Punson, I. Dueramae, A. Somwangthanaroj, and S. Tiptipakorn, "Rheological and thermomechanical characterizations of fumed silica-filled polybenzoxazine nanocomposites," Engineering Journal, vol. 15, no. 3, pp. 27-38, 2011.

[17] V. Ayel, O. Lottin, and H. Peerhossaini, "Rheology, flow behavior and heat transfer of ice slurries: A review of the state of the art," International Journal of Refrigeration, vol. 26, pp. 95-107, 2003.

[18] H. Komono, F. Tamura, S. Sawada, and T. Asaoka, "Study on flow and heat transfer characteristics of ice slurry in the transition region," International Journal of Refrigeration, vol. 36, pp. 801-808, 2013.

[19] L. Chen, T. Wang, Y. Zhao, and X. R. Zhang, "Characterization of thermal and hydrodynamic properties for microencapsulated phase change slurry (MPCS)," Energy and Conversion Management, vol. 79, pp. 317-333, 2014. 